\title{
TREN KAJIAN AL-QUR'AN DI DUNIA BARAT
}

\author{
Yusuf Rahman \\ Dosen Fakultas Ushuluddin dan Sekolah Pascasarjana \\ UIN Syarif Hidayatullah Jakarta
}

\begin{abstract}
This research was partially take reference by Edward Said in his Orientalism in 1978 have criticized the Orientalists which he said was biased against Western thought and culture, Orientalist studies of the AlQur'an, we could divide them into two general categories, the first group "old" Orientalism (Orientalism "The Past"). This paradigm shift occurred from philological approach, criticism of the text of the Al-Qur'an to approach literature; study the Al-Qur'an in the Western world in recent years is very widespread and growing. In contrast to previous studies in the past were very much influenced by the spirit of colonialism, and orientalism misionarisme, study the Al-Qur'an in recent years shows an understanding and appreciation of intellectual property.
\end{abstract}

Kata kunci: paradigma, orientalisme, kolonialisme

\section{Pendahuluan}

Pertama, sebelum membahas lebih lanjut tema ini, perlu dijelaskan terlebih dahulu yang dimaksud dengan Barat dalam tulisan ini. "Barat" biasanya diasosiasikan dengan para Orientalis, yaitu para sarjana Barat yang mempelajari budaya dan tradisi Timur. Orientalis berasal dari kata bahasa Latin oriens, Timur. Edward Said dalam karyanya Orientalism ${ }^{1}$ pada tahun 1978 telah mengkritisi para Orientalis yang menurutnya sangat bias terhadap budaya dan pemikiran Barat. Untuk masa kolonial di abad kesembilan belas dan awal abad keduapuluh, kajian-kajian seperti ini memang marak, seperti yang nanti akan didiskusikan. Namun, di antaranya berkat kritikan keras dari Edward Said, kajian-kajian sarjana Barat terhadap Islam dan al-Qur'an pada abad keduapuluh dan keduapuluh satu sudah mulai berubah dan beragam.

Selain itu, ketika berbicara Barat, kita juga harus menyadari bahwa di Barat tidak hanya sarjana non-Muslim yang mengkaji Islam dan al-Qur'an, namun banyak juga sarjana Muslim yang tinggal dan mengajar di Barat dan menulis beberapa kajian tentang Islam dan al-Qur'an. Oleh karena itu, dalam tulisan ini, dunia Barat, tidak hanya dibatasi pada sarjana Barat non Muslim namun juga sarjana Muslim yang menulis di Barat, seperti Fazlur Rahman, Khalid Abu el-Fadl, Abdullahi Ahmed an-Naim, Amina Wadud, Asma Barlas, Nasr Hamid Abu Zayd, dan lainnya.

Kedua, dalam tulisan ini, penulis lebih memilih tema kajian al-Qur'an daripada kajian tafsir, karena sarjana-sarjana di Barat tidak hanya mengkaji tafsir, namun juga mengkaji teks alQur'an, sejarah al-Qur'an, periodisasi al-Qur'an, kandungan al-Qur'an, ulum al-Qur'an,

${ }^{1}$ Buku ini sudah diterjemahkan oleh Asep Hikmat ke bahasa Indonesia dengan judul Orientalisme (Bandung: Pustaka, 1984). Lihat juga tulisan Jacques Waardenburg, "Mustashrikûn,” Encyclopaedia of Islam (Leiden: E.J. Brill, 1960-), 7: 735- 
terjemahan al-Qur'an, dan lain-lain. Oleh karena itu sebenarnya kajian-kajian al-Qur'an oleh sarjana-sarjana di Barat sangat kaya dan layak dikaji karena dapat memperkaya wawasan kita, walaupun kita harus tetap kritis terhadap karya-karya tersebut. Bahkan Gabriel Said Reynolds menyatakan bahwa kajian al-Qur'an di Barat saat ini telah mencapai masa keemasannya "the golden age of Qur'anic studies has arrived."'2 Oleh karena kajian para sarjana di Barat sangat banyak, dan tidak mungkin untuk dibahas satu persatu dalam tulisan ini, maka tulisan ini hanya akan membahas beberapa karya yang cukup berpengaruh saja.

\section{Kategori Umum Kajian Orientalis}

Di dalam mendiskusikan kajian Orientalis terhadap al-Qur'an, kita dapat membagi mereka ke dalam dua kategori umum, yaitu pertama kelompok "old" Orientalism (Orientalisme "Masa Lalu”). Lihat saja Ignaz Goldziher yang wafat tahun 1921, Theodor Noldeke (m. 1930), Edward Sell (m. 1932), Arthur Jeffery (m. 1959).

Kelompok ini di dalam beberapa karyanya lebih mengutamakan kajian kepada what is behind the text (apa yang ada di balik teks/al-Qur'an). Karya Edward Sell yang berjudul Historical Development of the Qur'an, A. Mingana tentang Syiriac Influence on the Style of the Kur'an, A. Jeffery tentang The Foreign Vocabulary of the Qur'an, dan juga yang lain, masuk dalam kategori ini, karena membahas sesuatu sebelum al-Qur'an terbentuk, seperti pengaruh luar terhadap al-Qur'an dan juga sejarah kemunculan al-Qur'an. Hal ini dilakukan dengan menggunakan metodologi filologi, textcriticism, form criticism dan lainnya.

Banyak juga karya Orientalis yang tidak setuju dengan pandangan mereka dan mengajukan pandangan yang jauh berbeda. Bahkan, beberapa pengamat kajian al-Qur'an menyatakan bahwa saat ini telah terjadi "perubahan paradigma" (shift of paradigm) dalam kajian al-Qur'an. ${ }^{3}$ Kalau kajian kelompok pertama lebih terfokus pada what is behind the text(apa yang ada di belakang teks), paradigma kelompok yang kedua adalah what is before/in front of the text (apa yang ada di hadapan teks/al-Qur'an) seperti bagaimana al-Qur'an telah dan selalu memberikan pengaruh kepada orang yang membacanya/mendengarnya, bagaimana para pembaca/pendengar menerima dan memahami al-Qur'an.

Perubahan paradigma ini terjadi dari pendekatan filologis, text criticismterhadap al-Qur'an ke pendekatan sastra. Buku The Literary Structures of Religious Meaning in the Qur'an (LSRMQ) yang diedit oleh Issa J. Boullata ${ }^{4}$ adalah merupakan salah satu contoh dari perubahan paradigma ini. Di dalam karya ini, beberapa Orientalis seperti Boullata, A. Neuwirth, A.H. Johns, A.M. Zahniser, Michael Sells, dan A.T. Welch mengkaji dan mengapresiasi gaya sastra al-Qur'an. Boullata, seorang penganut agama Kristen dari Palestina, banyak menulis dan mengapresiasi kemukjizatan al-Qur'an. A. Neuwirth, salah satu sarjana wanita pengkaji al-Qur'an dan sastra Arab dari Jerman, menulis disertasinya tentang kesatuan tema dalam al-Qur'an, dan kini banyak mempublikasikan beberapa tulisan yang menentang pandangan J. Wansbrough dan A. Rippin.

${ }^{2}$ Gabriel Said Reynolds, “Introduction: The Golden Age of Qur'anic Studies?,” dalam Gabriel Said Reynolds (ed.), New Perspectives on the Qur'ân: The Qur'an in Its Historical Context 2 (London dan New York: Routledge, 2011), 2.

${ }^{3}$ Stefan Wild, "Preface," in The Qur'an as Text, ed. S. Wild (Leiden: Brill, 1996), viii.

${ }^{4}$ Diterbitkan di Richmond, Surrey: Curzon Press, 2000. 
Selain pembedaan di atas, para pengkaji karya-karya Orientalis biasanya juga membedakan kajian Orientalis kepada kajian revisionis dan tradisionalis. Kelompok revisionis adalah para sarjana yang selalu meragukan dan mempertanyakan klaim umat Islam atas kebenaran tradisi-tradisi Islam namun, menurut mereka, klaim tersebut tidak didukung dengan bukti yang kuat dan tidak bias, sementara kelompok tradisionalis adalah para sarjana Barat yang mempercayai klaim umat Islam tersebut dengan tanpa mempertanyakannya. ${ }^{5}$

Kajian-kajian al-Qur'an yang termasuk dalam kajian revisionis adalah karya John Wansbrough Quranic Studies: Sources and Methods of Scriptural Interpretation. Di antara kesimpulan Wansbrough adalah pernyataannya bahwa redaksi final al-Qur'an baru selesai 150 tahun setelah Nabi Muhammad wafat. ${ }^{6}$ Kesimpulan ini tentu saja berbeda dengan kesimpulan mayoritas umat Islam yang menyatakan bahwa al-Qur'an telah selesai dan lengkap sebelum Nabi Muhammad wafat.

Banyak sarjana yang juga mengadopsi pendekatan revisionis ini, baik dalam mengkaji alQur'an, tafsir, fiqh maupun bidang lainnya, seperti Andrew Rippin, Gerald Hawting, Patricia Crone, Michael Cook, Christoph Luxenberg, and Gerd Puin. ${ }^{7}$

Andrew Rippin, misalnya, dapat dikatakan sebagai murid setia John Wansbrough. Walaupun sebenarnya dia menulis disertasi tentang Asbâb al-Nuqû̉l di McGill University Kanada yang dibimbing oleh Prof. Charles Adams, tapi ia lebih banyak belajar dan mengerjakan disertasinya di SOAS (School of Oriental and African Studies) di Inggris bersama John Wansbrough. Banyak karya-karya Rippin, yang kini dapat dibaca dalam The Qur'an and Its Interpretative Tradition, tentang beberapa tema kajian al-Qur'an dan tafsir, dan membahas sejarah perkembangan tafsir. Salah satu yang menjadi konsern utamanya adalah tafsir pada masa awal Islam. Dalam hal ini ia banyak mengkritik para sarjana yang mengaminkan begitu saja klaim para ulama tentang karya-karya sarjana Muslim, seperti Ibn 'Abbâs. Berdasarkan kajian terhadap teks dan manuskrip yang ada di beberapa negara, ia menyimpulkan bahwa sebenarnya beberapa karya Ibn 'Abbâs antara satu dengan lainnya sama saja, namun diberi judul berbeda-beda. ${ }^{8}$

Pertanyaan mendasar yang diajukan kelompok revisionis adalah "apa buktinya" Apa buktinya bahwa al-Qur'an sudah final pada masa Nabi? Apa buktinya bahwa al-Qur'an dikodifikasi pada masa khalifah Usman? Dan bukti yang diharapkan dari kelompok revisionis ini adalah bukti historis yang tidak bias, dan akan lebih baik dari sumber non-Islam. Kelompok revisionis menyangsikan dan kurang mempercayai sumber-sumber Muslim, karena bagi mereka sumber-sumber tersebut termasuk dalam "Sejarah Penyelamatan" (salvation history). Sumber-

${ }^{5}$ Lihat pembagian J. Koren and Y. D. Nevo, "Methodological Approaches to IslamicStudies,” Der Islam 68 (1991): $87-$ 107. Lihat Juga A. Rippin, "Foreword," dalam Quranic Studies: Sources and Methods of Quranic Interpretation (Amherst New York: Prometheus Books, 2004), xii.

${ }^{6}$ Lihat pembahasan Rippin tentang tesis Wansbrough dalam tulisannya "Literary Analysis of Qur'an, Sira and Tafsir: The Methodologies of John Wansbrough," in Approaches to Islam in Religious Studies, ed. R. C. Martin (Tucson, AZ, 1985), 151-163, 227-232. Sudah diterjemahkan ke bahasa Indonesia “Analisis Sastra terhadap al-Qur'an, Tafsir dan Sirah: Metodologi John Wansbrough," dalam Richard Martin (ed.), Pendekatan Kajian Islam dalam Studi Agama, terjemahan Zakiyuddin Baidhawy (Surakarta: Muhammadiyah University Press, 2001), 201-222.

${ }^{7}$ Lihat Abdullah Saeed, The Qur'an: An Introduction (New York: Routledge, 2008), 108.

${ }^{8}$ Lihat di antaranya Rippin, "Tafsir Ibn 'Abbas and Criteria for Dating Early taisir Texts," Jerusalem Studies in Arabic and Islam 18 (1994): 38-83, Rippin, "Ibn 'Abbas's al-Lughât fi1-Qur'ân,” BSOAS 44 (198 1): 15-2 5; dan Rippin, "Ibn 'Abbas's Gharîb al-Qur'ân," BSOAS 46 (1983): 332-333. 
sumber tersebut tidak berbicara "what really have happened" (apa yang sebenarnya terjadi), akan tetapi "what they believe/assume have really happened" (apa yang mereka yakini benarbenar telah terjadi"). ${ }^{9}$ Argumen mereka "kita tidak tahu dan mungkin tidak pernah dapat mengetahui apa yang sesungguhnya terjadi; semua yang kita ketahui sekarang adalah apa yang dipercaya telah terjadi oleh orang yang datang kemudian, seperti terekam dalam Sejarah Penyelamatan."10

Jika kelompok revisionis menyangsikan kesimpulan-kesimpulan yang terdapat dalam tradisi Islam karena ketiadaan bukti yang kuat, kelompok Orientalis yang lain, yang disebut dengan kelompok tradisionalis, mempercayai kesimpulan-kesimpulan yang terdapat dalam tradisi Islam, selama belum ada bukti yang mengatakan sebaliknya. W.M. Watt, W.C. Smith, Issa J. Boullata dan Wael B. Hallaq, adalah di antara sarjana yang dapat dikategorikan dalam kelompok kedua ini. Pendekatan ini oleh Charles J. Adams disebut dengan pendekatan irenic, yaitu pendekatan yang menghargai kebenaran keberagamaan orang lain. ${ }^{11}$ Wilfred Cantwell Smith, pendiri the Institute of Islamic Studies di McGill University Kanada mengatakan bahwa pernyataan kita tentang suatu agama baru bisa dikatakan benar, jika pemeluk agama tersebut mengkonfirmasi kebenaran pernyataan kita.

\section{Respon Sarjana Muslim terhadap Kajian Orientalis}

Sarjana Muslim berbeda-beda di dalam merespon karya para Orientalis. Tentu saja mayoritas di antara mereka menentang kajian para Orientalis, terutama yang revisionis. Kalau kita membaca beberapa artikel dan buku yang ada kita dapatkan "caci maki" mereka terhadap kajian Orientalis. Di Indonesia kita bisa menemukan beberapa tulisan tentang ini, misalnya Adnin Armas, Metodologi Bibel dalam Studi al-Qur'an: Kajian Kritis, ${ }^{12}$ dan Syamsuddin Arif, Orientalis \& Diabolisme Pemikiran. ${ }^{13}$

Di Barat, respon negatif terhadap karya Orientalis ditunjukkan oleh, misalnya M. AbdulRauf. Abdul-Rauf menyatakan dalam “'Outsiders' Interpretation of Islam: A Muslim's Point of View,"14 bahwa sarjana non-Muslim tidak berhak untuk berbicara tentang Islam, karena, menurut istilah Fazlur Rahman, mereka tidak mengalami dan menginternalisasi Islam dalam diri mereka. "Hanya orang yang pernah merasakan sakit gigi bisa menjelaskan sakitnya sakit gigi."

Ini tentu berbeda dengan respon Fazlur Rahman, yang walaupun mengkritisi beberapa kajian Orientalis, namun memberikan apresisasi terhadap kontribusi mereka dalam kajian Islam dan al-Qur'an. Rahman memberikan beberapa syarat agar kajian Orientalis bisa memiliki

\footnotetext{
${ }^{9}$ Lihat Rippin, “Analisis Sastra terhadap al-Qur'an, Tafsir dan Sirah,” 205-208.

${ }^{10}$ Rippin, “Analisis Sastra terhadap al-Qur'an, Tafsir dan Sirah,” 208.

${ }^{11}$ Lihat Charles J. Adams, "Islamic Religious Tradition," dalam The Study of the Middle East, L. Binder (ed.) (New York: Wiley, 1976), 38.

${ }^{12}$ Jakarta: Gema Insani Press, 2005.

${ }^{13}$ Jakarta: Gema Insani Press, 2008.

${ }^{14} \mathrm{M}$. Abdul-Rauf, “'Outsiders’ Interpretations of Islam: A Muslim's Point of View,” dalam R.C. Martin (ed.), Approaches to Islam in Religious Studies (Tucson: University of Arizona Press, 1985), 179-188. Sudah diterjemahkan ke bahasa Indonesia”Interpretasi Orang Luar tentang Islam: Studi Pandang Muslim,” 237-248. Untuk respon sarjana-sarjana Muslim lainnya, lihat Rippin, "Western Scholarship and the Qur'ân," The Cambridge Companion to the Qur'ân, Jane Dammen McAuliffe (ed.) (Cambridge, New York: Cambridge University Press, 2006), 245-247.
} 
pemahaman dan aprresiasi intelektual terhadap Islam, yaitu tidak berprasangka, sensitif dan berpengetahuan banyak. ${ }^{15}$ Di akhir tulisannya, Rahman berharap terwujudnya kajian Islam yang lebih sehat dan lebih kaya akan muncul di masa yang akan datang.

\section{Kajian Sarjana di Barat terhadap al-Qur'an pada Masa Kini}

Sebagaimana disampaikan oleh Reynolds, kajian al-Qur'an di dunia Barat telah mencapai "the golden age" dan mencakup berbagai bidang kajian. Di samping itu, fenomena yang menarik adalah bahwa telah terjadi kolaborasi antara sarjana Muslim dan sarjana non Muslim dalam mengkaji Islam dan al-Qur'an. Dengan keberadaan beberapa sarjana Muslim yang tinggal dan mengajar di negara Barat, kolaborasi ini semakin mudah dilakukan. Salah satu contoh utama kolaborasi ini adalah terbitnya The Encyclopaedia of the Qur'an, sebanyak 5 jilid, yang diedit oleh Jane D. McAuliffe, di mana sarjana non Muslim dan juga sarjana Muslim membahas beberapa kata, konsep, tempat, dan juga beberapa penafsiran terhadap suatu tema dalam al-Qur'an. ${ }^{16}$ Pada tahun 2007 juga terbit buku referensi penting tentang al-Qur'an dalam bahasa Perancis berjudul Dictionnaire du Coran, yang ditulis oleh beberapa sarjana dengan bahasa Perancis. ${ }^{17}$ Buku-buku ini, terutama yang pertama, pastinya akan menjadi buku referensi penting tentang kajian al-Qur'an.

Selain buku referensi di atas, Reynolds ${ }^{18}$ juga menjelaskan beberapa buku referensi yang dipublikasikan di Eropa. Pertama tentang kamus al-Qur'an untuk memudahkan para pembaca memahami makna al-Qur'an, seperti A Concise Dictionary of Koranic Arabic oleh Arne A. Ambros dan Stepan Prochazka, ${ }^{19}$ serta The Arabic - English Dictionary of Qur'anic Usage oleh Elsaid Badawi dan Muhammad Abdel Haleem. ${ }^{20}$

Selain kamus al-Qur'an, beberapa terjemahan terhadap al-Qur'an dalam berbagai bahasa Eropa juga dapat ditemukan, baik yang ditulis oleh sarjana Muslim maupun non Muslim, seperti MAS. Abdel Haleem dengan judul The Qur'ân, ${ }^{21}$ Tarif Khalidi, The Qur'an: A New Translation. ${ }^{22}$ Sementara dari non Muslim ada Alan Jones dengan judul The Qur'an, ${ }^{23}$ dan Harmut Bobzin Der Koran. ${ }^{24}$ Menarik untuk dikaji bagaimana subyektifitas penerjemah mempengaruhi kegiatan penerjemahan al-Qur'an.

Jane D. McAuliffe, yang telah menulis beberapa artikel dan buku tentang kajian al-Qur'an dan mengedit The Encyclpaedia of the Qur'an, juga mengedit sebuah buku berjudul The Cambridge Companion to the Qur'an dengan mengajak sarjana non Muslim dan juga Muslim untuk membahas beberapa aspek tentang sejarah teks al-Qur'an hingga penafsiran al-Qur'an. ${ }^{25}$ Sarjana Muslim

\footnotetext{
${ }^{15}$ F. Rahman, "Pendekatan terhadap Islam dalam Studi Agama," 259.

${ }^{16} J a n e$ D. McAuliffe (ed.), The Encyclopaedia of Islam, 5 jilid (Leiden: Brill, 2001-2006).

${ }^{17}$ Diedit oleh M.A. Amir-Moezzi (Paris: Laffont, 2007).

${ }^{18}$ Lihat Reynolds, “The Golden Age of Qur'ânic Studies," 5 dst.

${ }^{19}$ Wiesbaden: reichert, 2004.

${ }^{20}$ Leiden: Brill, 2008.

${ }^{21}$ Oxford: Oxford University Press, 2004.

${ }^{22}$ London: Penguin Classics, 2008.

${ }^{23}$ Exeter: Gibb Memorial Trust, 2007.

${ }^{24}$ Munich: Beck, 2010.

${ }^{25}$ Jane D. McAuliffe (ed.), The Cambridge Companion to the Qur'ân (Cambridge dan New York: Cambridge University
} Press, 2006), 
yang ikut berpartisipasi dalam penulisan buku ini adalah Navid Kermani, Asma Barlas dan Abdulaziz Sachedina, yang masing-masing membahas aspek aestetik dari al-Qur'an, penafsiran jender dan hubungan antara Islam dengan agama yang lain. Di samping itu, A. Rippin mengedit buku dengan judul The Blackwell Companion to the Qur'ân ${ }^{26}$ yang membahas berbagai pendekatan untuk mengkaji teks al-Qur'an, tema-tema al-Qur'an, dan berbagai bentuk penafsiran al-Qur'an, seperti penafsiran Sunni, penafsiran sufistik, penafsiran Syi'ah Ismailiyyah dan Ithna Asy'ariyyah, dll. Kedua buku ini saling melengkapi dan ditulis oleh para sarjana dalam bidangnya, dan juga diperuntukkan untuk mereka yang ingin tahu lebih jauh tentang al-Qur'an dan isinya.

Selain kumpulan artikel dalam ensiklopedia dan "companion", beberapa buku terbit yang merupakan hasil dari seminar internasional tentang kajian al-Qur'an. Reynolds mencatat pertama adalah konferensi yang diadakan pada bulan Januari 21-25 tahun 2004 dengan judul "Historische Sondierung und methodische Reflexionen zur Koranexegese - Wege zur Rekonstruktion des vorkanonischen Koran.” Penyelenggaranya adalah Angelika Neuwirth, Nicolai Sinai dan Michel Marx dari Free University, Berlin. Paper-paper dari seminar ini kemudian diterbitkan dalam bahasa Inggris dengan judul The Qur'ân in Context: Historical and Literary Investigations in the Qur'ânic Milieu. ${ }^{27}$ Sebagaimana dapat dibaca dari judulnya, kajian ini menggabungkan antara pendekatan historis dan sastra. Penting untuk dicatat bahwa Angelika Neuwirth merupakan salah satu sarjana yang banyak mengkritisi karya-karya kelompok revisionis.

Selain di Free University Berlin, di Jerman juga terdapat pusat kajian al-Qur'an yang bernama Inarah: Institute zur Erfoschung der fruehen Islamgescichte und des Koran, yang dipimpin GerdR. Puin dan Karl Heinz Ohlig. Berbeda dengan pusat kajian yang di Free University, pusat kajian ini sangat kentara proyek "radical historical revisionism". ${ }^{28}$ Pusat kajian ini telah mempublikasikan empat buku antara tahun 2005 - 2009 yang mengkaji secara kritis tentang asal usul Islam dan alQur'an, seperti Die dunklen Anfaenge: Neue Forschungen zur Entstehung und fruehen Geschichte des Islam, Der fruehe Islam, Schlaglichter: die bieden ersten islamischen Jahrbunderte, dan Vom Koran zum Islam. ${ }^{29}$

Selain konferensi yang diadakan di Jerman, beberapa konferensi juga diadakan di Amerika Serikat. Pertama konferensi yang diketuai Reynolds yang diadakan di University of Notre Dame pada bulan April 2005 dengan tema "Towards a New Reading of the Qur'ân?" yang kemudian menghasilkan buku dengan judul The Qur'an in Its Historical Context. ${ }^{30}$ Reynolds menyatakan bahwa konferensi ini diadakan untuk mengkritisi pemikiran kelompok revisionis atas dasar argumentasi dan teori mereka, dan juga untuk mengkaji al-Qur'an dan hubungannya dengan konteksnya, yaitu Late Antiquity.

Pada bulan April 2009, Reynolds mengadakan Notre Dame Qur'an Conference yang kedua yang menghasilkan buku dengan judul New Perspectives on the Qur'ân: The Qur'an in Its Historical Context. ${ }^{31}$ Yang penting dicatat dari konferensi dan buku ini, kata Reynolds, adalah pertama

\footnotetext{
${ }^{26}$ A. Rippin, The Blackwell Companion to the Qur'ân (Oxford: Blackwell, 2006).

${ }^{27}$ Leiden: Brill, 2010.

${ }^{28}$ Reynolds, "Introduction: The Golden Age of Qur'ânic Studies," 8.

${ }^{29}$ Lihat Reynolds, "Introduction: The Golden Age of Qur'ânic Studies," 8.

${ }^{30}$ Reynolds (ed.), The Qur'ân in Its Historical Context (London dan New York: Routledge, 2007).

${ }^{31}$ Reynolds (ed.), New Perspectives on the Qur'ân: The Qur'an in Its Historical Context 2 (London dan Newyork: Routledge,
} 2011). 
mulai banyaknya sarjana Muslim yang terlibat dalam kajian kritis terhadap al-Qur'an, dan kedua, kebanyakan kajian terkini terhadap al-Qur'an, walaupun masih ada kajian yang bersifat polemik, secara garis besar dipengaruhi oleh respon yang simpatik terhadap teks al-Qur'an. Para sarjana yang terlibat dalam kajian ini lebih termotivasi oleh apresiasi intelektual mereka terhadap alQur'an, dari pada untuk kepentingan polemik.

Berdasarkan catatan Reynolds ini, penting kemudian bagi para sarjana Muslim untuk ikut terlibat dalam kajian-kajian akademik terhadap al-Qur'an. Saat ini, sarjana-sarjana Muslim yang terlibat, baik dengan menggunakan pendekatan tradisional maupun kritis, dalam kajian al-Qur'an, belum terlalu banyak. Beberapa di antara mereka bahkan saat ini sudah tiada, seperti Fazlur Rahman, Nasr Hamid Abu Zayd, Mohammed Arkoun. Beberapa karya mereka telah banyak menggugah pemikiran kebanyakan umat Islam. Fazlur Rahman dengan pendekatan "double movement"nya, Nasr Abu Zayd dengan "hermeneutika"nya dan Arkoun dengan "deconstruction strategy"nya.

Tentu saja, pemikiran dan metode kajian yang mereka ajukan tidak begitu saja diterima oleh masyarakat Muslim. Itu kenapa di antaranya mereka tinggal dan mengajar di negara Barat dan tidak di negara Muslim. Yang pertama, dalam konteks luas, sangat menghargai kebebasan akademik, sementara di negara Muslim, kajian yang berbeda dan "bertentangan" dengan pandangan masyarakat Muslim dianggap sesat dan dengan demikian dicap kafir.

Selain para sarjana Muslim di atas yang berkiprah di Barat, terdapat beberapa sarjana Muslim yang telah menggunakan pendekatan-pendekatan baru dan modern, seperti pendekatan jender yang diusung oleh Rif'at Hassan, Aminah Wadud, Asma Barlas, pendekatan teologi pembebasan yang diusung Farid Esack dan Asghar Ali Engineer, pendekatan hubungan antar umat beragama yang diusung Abdulaziz Sachedina.

Terakhir, fenomena yang menarik dalam kajian al-Qur'an di Barat adalah fenomena online resource dalam kajian al-Qur'an. Reynolds mencatat beberapa alamat website yang dapat digunakan untuk melihat, membaca dan mendownload kajian al-Qur'an. ${ }^{32}$ Pertama website yang dibuat oleh Mehdi Azaiez dalam bahasa Perancis dengan alamat (<http://mehdiazaiez.org) yang memberikan informasi tentang konferensi-konferensi dan publikasi-publikasi dalam kajian al-Qur'an. Di samping itu, terdapat website (<http://www.quranbrowser.com) serta (<www.altafsir.com) yang menyediakan beberapa terjemahan al-Qur'an serta tafsir alQur'an. Selain itu ada website (<www.studyquran.co.uk) yang menawarkan berbagai fasilitas, seperti penyusuran makna kata, kamus, gramatika, bahkan mengkaitkannya dengan entri di Lexicon karya E.W. Lane.

Perkembangan terakhir adalah terbentuknya asosiasi internasional pengkajian al-Qur'an, yaitu International Qur'anic Studies Association dengan alamat websitenya (<iqsaweb.wordpress.com) yang memuat berbagai informasi tentang konferensi, publikasi dan rujukan-rujukan tentang kajian al-Qur'an. Bahkan, IQSA juga memiliki facebook International Qur'anic Studies Association dan juga twitter@iqsaweb. Perkembangan terakhir ini sangat membantu untuk mengetahui kajian-kajian terkini tentang al-Qur'an, yang tidak hanya terjadi di Barat, namun juga di Timur Tengah dan di Asia Tenggara.

\footnotetext{
${ }^{32}$ Reynolds, "Introduction: The Golden Age of Qur'ânic Studies," 7.
} 


\section{Penutup}

Kajian al-Qur'an di dunia Barat pada akhir-akhir ini sangat marak dan berkembang. Berbeda dengan kajian di masa sebelumnya yang sangat dipengaruhi dengan semangat kolonialisme, misionarisme dan orientalisme, kajian al-Qur'an pada beberapa tahun terakhir ini menunjukan pemahaman dan apresiasi intelektual yang lebih baik. Walaupun masih ada beberapa kajian yang menggunakan pendekatan historis revisionis, namun banyak juga yang mengkajinya dengan pendekatan yang berbeda-beda.

Perkembangan ini juga disebabkan keterlibatan aktif beberapa sarjana Muslim dalam kajian akademik di seminar-seminar dan publikasi ilmiah. Oleh karena itu, sangat dibutuhkan munculnya para pengkaji dan sarjana Muslim yang dapat merespon tantangan dan harapan ini.

\section{DAFTAR PUSTAKA}

Abdul-Rauf M., (1985). “Outsiders' Interpretations of Islam: A Muslim's Point of View,” dalam R.C. Martin (ed.), Approaches to Islam in Religious Studies. Tucson: University of Arizona Press

Adams, Charles J., (1976) "Islamic Religious Tradition," dalam The Study of the Middle East, L. Binder (ed.). New York: Wiley

Koren, J. and Y. D. Nevo, (1991) "Methodological Approaches to IslamicStudies, 'Der Islam 68

Martin, Richard (ed.), (2001). Pendekatan Kajian Islam dalam Studi Agama, terjemahan Zakiyuddin Baidhawy. Surakarta: Muhammadiyah University Press

McAuliffe, Jane D. (ed.), (2006), The Cambridge Companion to the Qur'ân. Cambridge dan New York: Cambridge University Press

-, (ed.), (2001-2006). The Encyclopaedia of Islam, 5 jilid. Leiden: Brill

Reynolds, Gabriel Said, (ed.), (2011). New Perspectives on the Qur'ân: The Qur'an in Its Historical Context 2. London dan New York: Routledge

-, (ed.), (2007) The Qur'an in Its Historical Context. London dan New York: Routledge

Rippin A., (1994). "Tafsir Ibn 'Abbas and Criteria for Dating Early taisir Texts," Jerusalem Studies in Arabic and Islam 18

- (2004). "Foreword," dalam Quranic Studies: Sources and Methods of Quranic Interpretation Amherst New York: Prometheus Books

—, (2006). "Western Scholarship and the Qur'ân," The Cambridge Companion to the Qur'ân, Jane Dammen McAuliffe (ed.). Cambridge, New York: Cambridge University Press - (2006). The Blackwell Companion to the Qur'an. Oxford: Blackwell Saeed, Abdullah, (2008). The Qur'an: An Introduction New York: Routledge Waardenburg, Jacques, (1960). "Mustashrikêun,” Encyclopaedia of Islam Leiden: E.J. Brill Wild, Stefan, (1996). "Preface," in The Qur'an as Text, ed. S. Wild Leiden: Brill 